\title{
Pharmacogenomics of cytochrome P450 3A4: recent progress toward the "missing heritability" problem
}

\author{
Kathrin Klein ${ }^{1,2}$ * and Ulrich M. Zanger ${ }^{1,2}$ \\ ${ }^{1}$ Dr. Margarete Fischer Bosch Institute of Clinical Pharmacology, Stuttgart, Germany \\ 2 University of Tübingen, Tübingen, Germany
}

\section{Edited by:}

José A. Agúndez, University of

Extremadura, Spain

\section{Reviewed by:}

Elena García-Martín, Universidad de Extremadura, Spain

Eric Gamazon, University of Chicago, USA

\section{*Correspondence:}

Kathrin Klein, Dr. Margarete Fischer Bosch Institute of Clinical

Pharmacology, Auerbachstr. 112, 70376 Stuttgart, Germany. e-mail:kathrin.klein@ikp-stuttgart.de
CYP3A4 is the most important drug metabolizing enzyme in adult humans because of its prominent expression in liver and gut and because of its broad substrate specificity, which includes drugs from most therapeutic categories and many endogenous substances. Expression and function of CYP3A4 vary extensively both intra- and interindividually thus contributing to unpredictable drug response and toxicity. A multitude of environmental, genetic, and physiological factors are known to influence CYP3A4 expression and activity. Among the best predictable sources of variation are drug-drug interactions, which are either caused by pregnane X-receptor (PXR), constitutive androstane receptor (CAR) mediated gene induction, or by inhibition through coadministered drugs or other chemicals, including also plant and food ingredients. Among physiological and pathophysiological factors are hormonal status, age, and gender, the latter of which was shown to result in higher levels in females compared to males, as well as inflammatory processes that downregulate CYP3A4 transcription. Despite the influence of these non-genetic factors, the genetic influence on CYP3A4 activity was estimated in previous twin studies and using information on repeated drug administration to account for $66 \%$ up to $88 \%$ of the interindividual variation. Although many single nucleotide polymorphisms (SNPs) within the CYP3A locus have been identified, genetic association studies have so far failed to explain a major part of the phenotypic variability. The term "missing heritability" has been used to denominate the gap between expected and known genetic contribution, e.g., for complex diseases, and is also used here in analogy. In this review we summarize CYP3A4 pharmacogenetics/genomics from the early inheritance estimations up to the most recent genetic and clinical studies, including new findings about SNPs in CYP3A4 (*22) and other genes (P450 oxidoreductase (POR), peroxisome proliferator-activated receptor alpha (PPARA)) with possible contribution to CYP3A4 variable expression.

Keywords: cytochrome P450, CYP3A4, pharmacogenomics, pharmacogenetics, drug metabolism, heritability

\section{CYP3A4 DRUG SUBSTRATES AND PHENOTYPING}

CYP3A4 is in the majority of individuals abundantly expressed in liver but population variability is extremely high $(>100$ fold). Average microsomal content has been estimated between $\sim 60 \mathrm{pmol} / \mathrm{mg}$ of microsomal protein (Ohtsuki et al., 2012), $110 \mathrm{pmol} / \mathrm{mg}$ (Klein et al., 2012), and $\sim 150 \mathrm{pmol} / \mathrm{mg}$ (WestlindJohnsson et al., 2003). Hepatic expression of the other CYP3A enzymes CYP3A5, CYP3A7, and CYP3A43 is much lower in adult Caucasians, although CYP3A5 may contribute up to about 50\% of the CYP3A pool in individuals with at least one CYP3A5*1 allele and with low CYP3A4 expression (Hustert et al., 2001a; Kuehl et al., 2001; Koch et al., 2002; King et al., 2003; Klees et al., 2005; McCune et al., 2005). The role of the minor CYP3A forms has been reviewed by others (Burk and Wojnowski, 2004; Daly, 2006). CYP3A4 is thus one of the most abundantly expressed cytochromes in human liver contributing on average about 15$30 \%$ to the microsomal P450 pool. Therefore and owing to their extraordinarily broad substrate selectivity CYP3A enzymes play a major role in the metabolism of $\sim 30-40 \%$ of all clinically used drugs (Evans and Relling, 1999; Zanger et al., 2008). These include preferentially lipophilic and bulky compounds from almost all therapeutic categories, including tacrolimus, cyclosporin A, erythromycin, ifosfamide, tamoxifen, benzodiazepines, several statins, antidepressants, opioids, and many more, as summarized in several previous reviews (Bu, 2006; Liu et al., 2007; Zanger et al., 2008). As CYP3A4 is also an efficient steroid hydroxylase, it has in addition an important role in the catabolism of several endogenous steroids like testosterone, progesterone, cortisol, and bile acids (Patki et al., 2003; Bodin et al., 2005).

The high sequence similarity of $>85 \%$ between the CYP3A isozymes CYP3A4 and CYP3A5 leads to highly similar substrate selectivity between these isoforms (Williams et al., 2002). CYP3A4 and CYP3A5 activities are therefore not specifically discriminable although some probe drugs showed higher selectivity for CYP3A4-including, for example, erythromycin $N$-demethylation (Wrighton et al., 1990) and atorvastatin ortho-hydroxylation (Feidt et al., 2010). Several in vivo test substrates are available and have been compared to each other, e.g., midazolam, erythromycin, quinine, and nifedipine (Liu et al., 2007). Endogenous marker activities have also been proposed as functional 
CYP3A-markers, including the $6 \beta$-hydroxylation of cortisol and the $4 \beta$-hydroxylation of cholesterol, but some limitations due to considerable intraindividual variability exist (Chen et al., 2006; Fuhr et al., 2007). Remarkably, however, data obtained with different CYP3A substrates or endogenous markers are not generally well correlated to each other and have therefore to be selected carefully with respect to the expected change in activity and design of the study (Galteau and Shamsa, 2003; Chen et al., 2006; Fuhr et al., 2007). Functional CYP3A phenotyping therefore continues to be a non-trivial problem.

\section{DEGREE OF HERITABILITY}

CYP3A4 drug oxidation phenotypes are highly variable but unimodally distributed. Nevertheless there is indication of substantial heritability. For example, antipyrine 4-hydroxylation rate, which is mainly catalyzed by CYP3A4 (Engel et al., 1996), was reported to be largely inherited (85\%) as shown in early twin studies (Penno et al., 1981). Moreover, a high degree of heritability for CYP3A4 drug oxidation capacity toward several of its substrates (erythromycin: 89\% and midazolam: 96\%) was estimated by a repeated drug administration approach (Ozdemir et al., 2000). A recent study used a classical twin model approach in combination with a St. John's Wort induction regimen and quinine sulfate metabolism as CYP3A4 activity measure to elucidate genetic versus non-genetic contribution to variable CYP3A4 induction. Although the uninduced levels were not recorded, the induced CYP3A4 activity heritability was estimated to be at least $66 \%$ and environmental factors like BMI, alcohol use, and smoking habit/quantity contributed at least $20 \%$ to the variability (Rahmioglu et al., 2011).

In contrast to the genetically polymorphic CYP2D6, which is mostly determined genetically with only minor contribution by environmental factors, most of the previously studied CYP3A4 polymorphisms are either rare or lack phenotypic effect and are thus unable to explain a sizeable fraction of heritable variation. The first documented CYP3A4 polymorphism is the frequently studied proximal promoter variant $C Y P 3 A 4^{*} 1 B(-392 \mathrm{~A}>\mathrm{G}, \mathrm{rs} 2740574)$ which occurs in white populations at $\sim 2-9 \%$ but at higher frequencies in Africans. This single nucleotide polymorphism (SNP) was initially found to be associated with higher tumor grade and stage in prostate cancer and showed higher nifedipine oxidase activity in human livers (Rebbeck et al., 1998). Association of $C Y P 3 A 4^{*} 1 B$ with markers of advanced disease was confirmed by some but not all further studies (Keshava et al., 2004; Perera et al., 2009). Although one in vitro study on the promoter variant found higher transcriptional activity in cell culture experiments using luciferase constructs, as well as changed protein binding by electrophoretic mobility shift assay (Amirimani et al., 2003), the functional effect of this variant remains questionable given the controversial data reported in several other in vitro and human liver studies (Wandel et al., 2000; Spurdle et al., 2002; Rodríguez-Antona et al., 2005; Klein et al., 2012). Also, a study with healthy volunteers phenotyped using the dextromethorphan/methoxymorphinan ratio failed to find an association of CYP $3 A 4^{*} 1 B$ or $* 2$ with CYP3A4 activity (García-Martín et al., 2002). Recently, resequencing and haplotype tagging studies have been carried out at the CYP3A locus in ethnically diverse populations (Thompson et al., 2006; Schirmer et al., 2007; Perera et al., 2009; Perera, 2010). These studies addressed the problem of "missing heritability" of CYP3A4 phenotype variability by considering haplotype structure at the CYP3A locus, which was found to be of some relevance. A markedly increased occurrence of rare variants and the presence of a homogeneous group of long-range haplotypes at high frequency were observed in nonAfrican populations (Thompson et al., 2004). Because of their involvement in the metabolism not only of naturally occurring foreign compounds, such as flavonoids, diterpenoids, and other herbal constituents (Zhou et al., 2007) but also of endogenous chemicals such as uroporphyrin (Franklin et al., 2000) it has been suggested that molecular adaptation to the changing environment may have occurred for genes at the CYP3A locus. Thus, it has been postulated that a region from about $40 \mathrm{~kb}$ upstream of the CYP3A4 gene promoter to intron 6 was under positive selection in humans (Thompson et al., 2004; Chen et al., 2009). In addition, despite the controversy about the $C Y P 3 A 4^{*} 1 B$ allele, a "high haplotype homozygosity" in European Caucasians in contrast to African Americans was observed, which may indicate a negative selection pressure that eliminated the ${ }^{*} 1 B$ allele in non-African populations (Schirmer et al., 2006). It should also be mentioned that interaction between SNP/haplotype and gender have been reported to impact on gene expression, further complicating the situation (Schirmer et al., 2007).

An intronic variant rs4646450, located in the CYP3A5 gene, has recently been associated with reduced tacrolimus dosage requirement in Japanese patients (Onizuka et al., 2011), with reduced endogenous serum dehydroepiandrosterone sulfate concentrations in over 14,000 individuals (Zhai et al., 2011) and was also associated with decreased protein expression and activity of CYP3A4 in human liver, explaining about $3-5 \%$ of hepatic variability (Klein et al., 2012). These data underline the importance of haplotype structure throughout the CYP3A locus, and they raise questions about causality of the various intronic and regulatory variants. It has been suggested generally that the most penetrant risk alleles may be of negative selective pressure and therefore be rare (Sadee, 2012). This may have led to their oversight in small sized screening studies or due to gene-environment interactions which can substantially mask genetic effects (Rahmioglu et al., 2011; Klein et al., 2012; Sadee, 2012).

Recently, however, an intron 6 variant rs35599367C > T (CYP3A4*22) was identified by a systematic screen for SNPs showing allelic mRNA expression imbalance in human liver (Wang et al., 2011). The effect of the variant was not confounded by sex or other variables and it accounted for $7 \%$ of the mRNA expression variability in a cohort of 93 liver samples. Expression in cultured cells transfected with minigenes containing exon 6, intron 6, and exon 7 reproduced the functional effect of the T-allele to decrease mRNA in vitro, suggesting that it could be the causal variant. As no associated splice variants or other hints to the exact mechanism were found, the variant was supposed to affect nascent RNA elongation rate (Wang et al., 2011; Sadee, 2012). In another recent study using 150 liver samples this variant was associated with decreased protein levels, but not when corrections were made for multiple testing (Klein et al., 2012).

Furthermore, the potential impact of CYP3A4 protein variants on drug-drug interaction was emphasized in a recent in vitro study 
using recombinantly expressed variant CYP3A4 proteins 3A4.2, 3A4.7, 3A4.16, and 3A4.18, where inhibitory profile differences of itraconazole and cimetidine were described in relation to the CYP3A4 variants (Akiyoshi et al., 2011). Thus, although most of the protein variants are too rare to make an impact on a population scale, individual carriers of such variants may have risk not only for impaired drug metabolism but also for a different drug-drug interaction profile.

\section{CYP3A4 POLYMORPHISMS - CLINICAL IMPACT}

Most previous clinical studies that implemented CYP3A genotyping are not considered here because they used mainly the $C Y P 3 A 5^{*} 3$ polymorphism as marker. The reader is referred to other reviews on this topic (Burk and Wojnowski, 2004; Daly, 2006). Table 1 shows a selection of CYP3A4-including pharmacogenetic in vivo studies. Although the effects of the novel intron 6 variant were not very pronounced in vitro, its impact became more apparent by in vivo pharmacokinetic and pharmacodynamic studies. Significant association of CYP3A4* 22 with decreased $\mathrm{AUC}_{0-\infty}$ ratio in atorvastatin-treated volunteers or 1.7- to 5-fold reduced statin dose of $\mathrm{T}$-allele carriers compared to non- $\mathrm{T}$ carriers to achieve optimal lipid control was shown in volunteer and clinical studies (Wang et al., 2011; Klein et al., 2012). The association of CYP3A4* 22 with simvastatin lipid-lowering response was shown in another clinical study (Elens et al., 2011a). Furthermore, renal transplant recipients who were carriers of the low-expressor Tallele had a $33 \%$ reduced mean daily-dose requirement to reach the same tacrolimus blood concentration compared to homozygotes for the wild type allele (Elens et al., 2011b) and 1.6- to 2.0-fold higher dose-adjusted trough blood levels of tacrolimus and cyclosporine $\mathrm{A}$ in stable renal transplant patients (Elens et al., 2012), both indicating lower CYP3A4 activity. Despite these consistent reports, the rather low frequency of the intron $6 \mathrm{SNP}$ [global minor allele frequency (MAF) 2.1\%, Caucasians 3-8\%] limits broader contribution to overall CYP3A4 variability.

\section{CYP3A4 POLYMORPHISMS - END OF THE ROPE?}

Databases are very helpful tools to get an overview on genetic variability. However, there are major collections which serve as basis for other online browsers (Table 2). The most important collection of data concerning cytochrome P450 gene haplotypes and in vitro as well as in vivo functional impact are summarized in the CYPallele homepage (updated last August 31, 2011) ${ }^{1}$. To date besides the reference CYP3A4* 1 another 21 alleles are included, comprising at least 21 amino acid changes and 2 frame shift variants. Although this collection is a useful resource for functional data related to the alleles, it only provides limited information on genetic variability. Further valuable information on CYP3A4 SNPs and clinical pharmacogenetics is available on the homepage of The Pharmacogenomics Knowledgebase PharmGKB ${ }^{2}$. More comprehensive genetic information can be obtained from other databases, which collect SNP data of diverse projects, but in contrast to the CYPallele database or PharmGKB they lack cross reference to documented functional impact (Table 2). The dbSNP

${ }^{1}$ http://www.cypalleles.ki.se/

${ }^{2} \mathrm{http}: / /$ www.pharmgkb.org/ database ${ }^{3}$ (build 137) currently provides information on 550 SNPs for the human CYP3A4 gene of which $21 \%$ are located within the coding region, including 61 non-synonymous amino acid changes, 18 synonymous, and 4 frameshift mutations. Remarkably, for most of the coding SNPs no MAF or reliable population related distribution data is yet available. This may soon be overcome by new data releases of the international "1000 Genomes Project." This large international collaborative project aims to generate a "Deep Catalog of Human Genetic Variation" including the entire spectrum of all types of DNA changes from SNPs and small indels (insertions/deletions) to large structural variations like copy number variants and large deletions and insertions, as well as frequency information and haplotype context (The 1000 Genomes Project Consortium, 2010) ${ }^{4}$. Next generation sequencing technologies are used to sequence the complete diploid genomes of 2500 unidentified individuals from about 25 different populations. With the release of the Integrated Phase 1 Variant set in May 2012 phased genotype calls on 1092 samples for SNPs, short indels, and large deletions from low-coverage sequencing became available. However, no functional or medical information is being collected. The potential of the 1000 Genomes Project for pharmacogenomics has been emphasized before (Gamazon et al., 2009). To illustrate how 1000 Genomes data may be used in pharmacogenetics for fine analysis, e.g., in search for causal variants, Figure 1 shows exemplarily the contribution of new SNP information to the genomic region of CYP3A flanking the CYP3A5*3 SNP rs776746 $( \pm 250 \mathrm{~kb})$. While in the HapMap data (Figure 1A) only eight SNPs were in strong linkage to rs776746, 49 SNPs from current 1000 Genomes dataset were identified to be in strong LD, and interestingly also some moderately linked SNPs are located within CYP3A4 (Figure 1B). Unfortunately, linkage information of SNPs with potential functional impact within the CYP3A4 gene, like* $1 B$ or $* 22$, is not available from both datasets, probably due to missing frequency data.

For the CYP3A4 gene the current 1000 Genomes database release (Integrated Phase 1 Variant Set; May 2012) contains in total 471 SNPs assigned to the major transcript (ENST00000336411), including NCBI dbSNP database content (build 134). The 1000 Genomes Project to date (accessed September 2012) contributed 129 new SNPs to this collection. Besides 115 intronic variant positions 7 non-synonymous amino acid changes were previously unknown, of which four variants were reported on the CYPallele homepage $(* 4, * 8, * 11, * 21)$ and only one was predicted to be deleterious by phenotype prediction tools SIFT and PolyPhen (Table 3). However, for most of the SNPs, availability of global MAF and population frequency data is still limited. Although most of the novel variants are rare, it should be noted that these can collectively make a marked contribution to the functional population variability. For individual patients, the combination of a rare deleterious variant with more frequent alleles of low function (compound heterozygosity) can be of predictive value. This was for example demonstrated for the polymorphic CYP2B6 in a large clinical study with HIV patients under efavirenz

\footnotetext{
${ }^{3}$ http://www.ncbi.nlm.nih.gov/projects/SNP

${ }^{4}$ http://www.1000genomes.org
} 

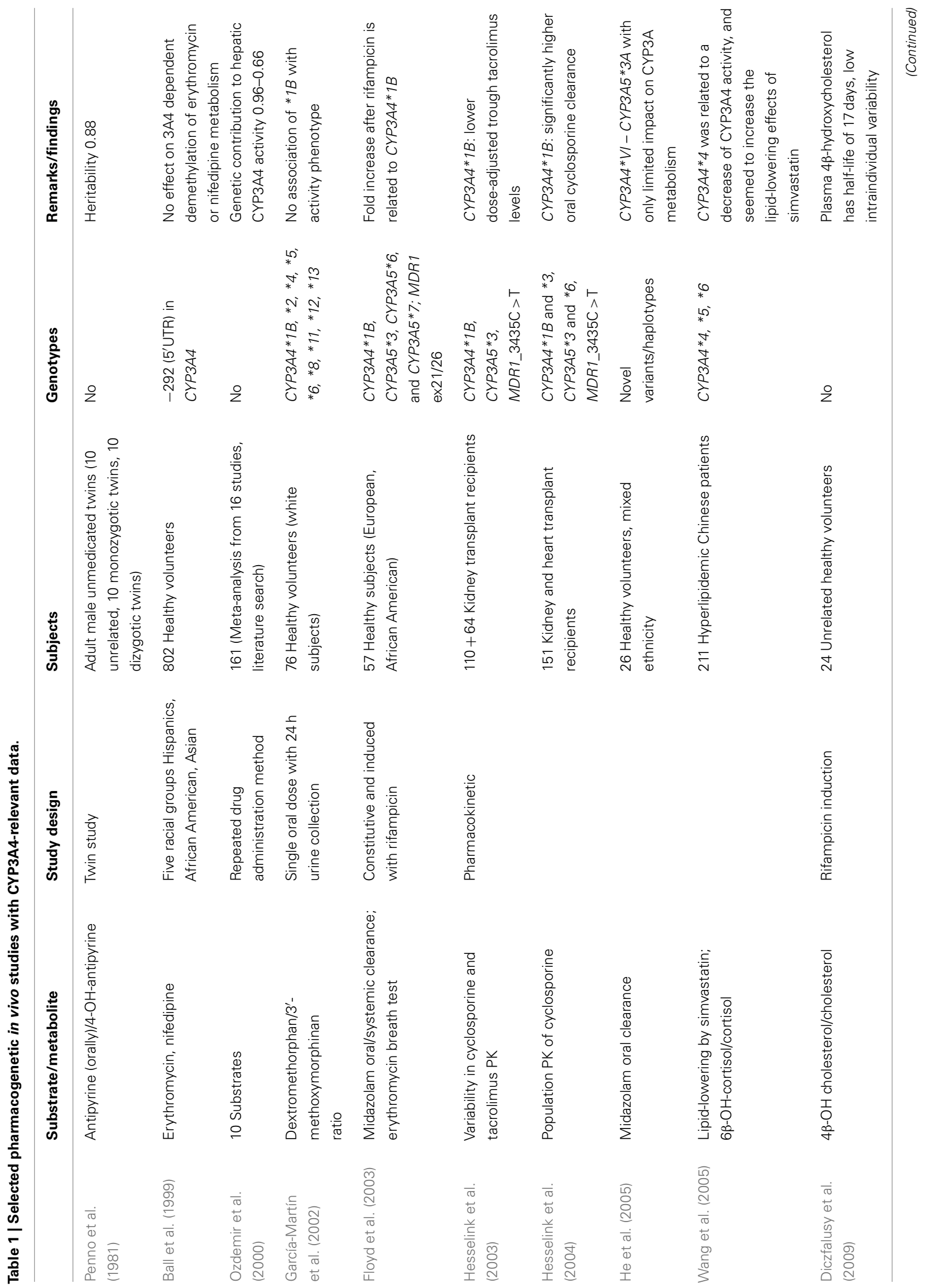


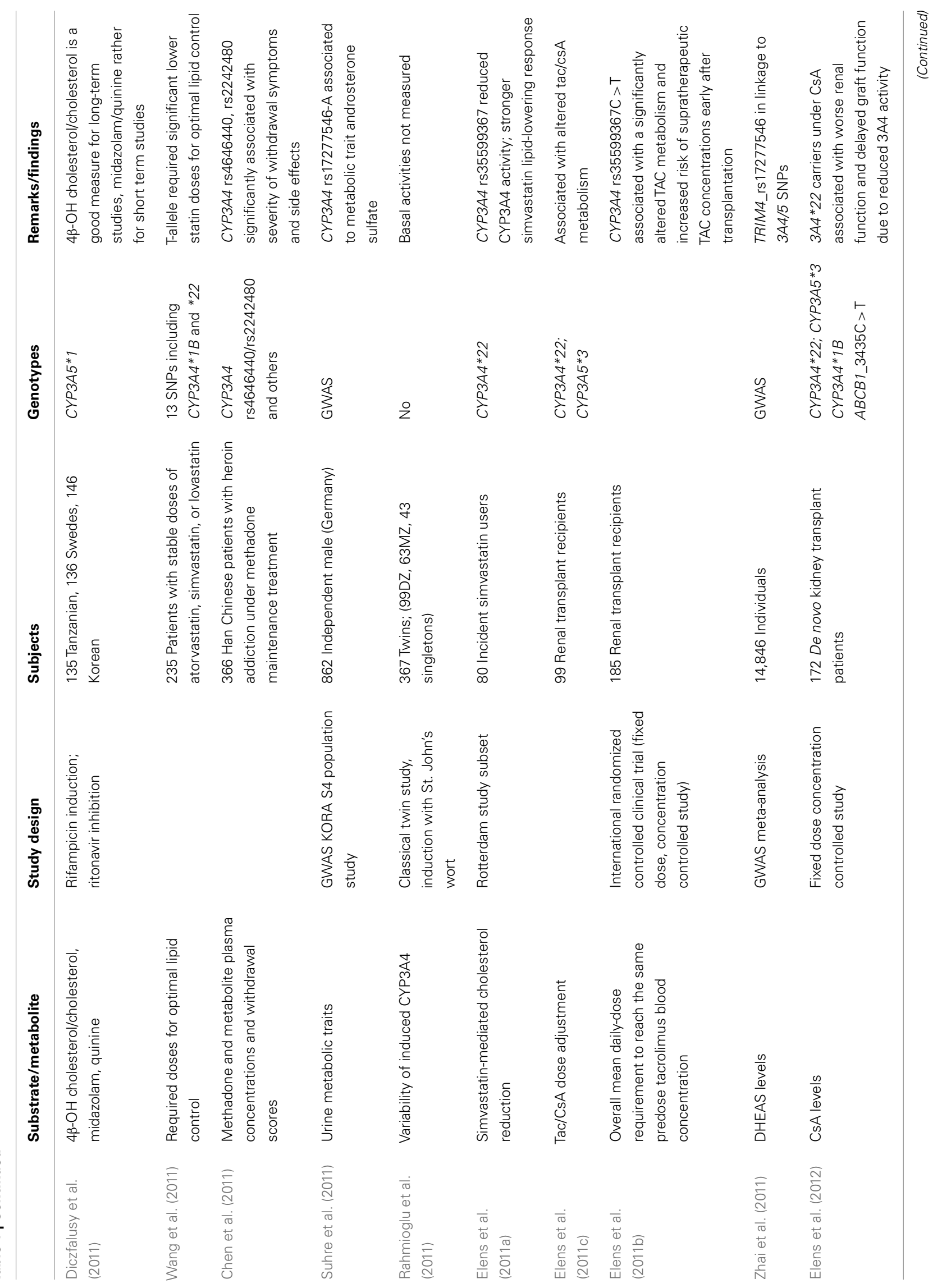




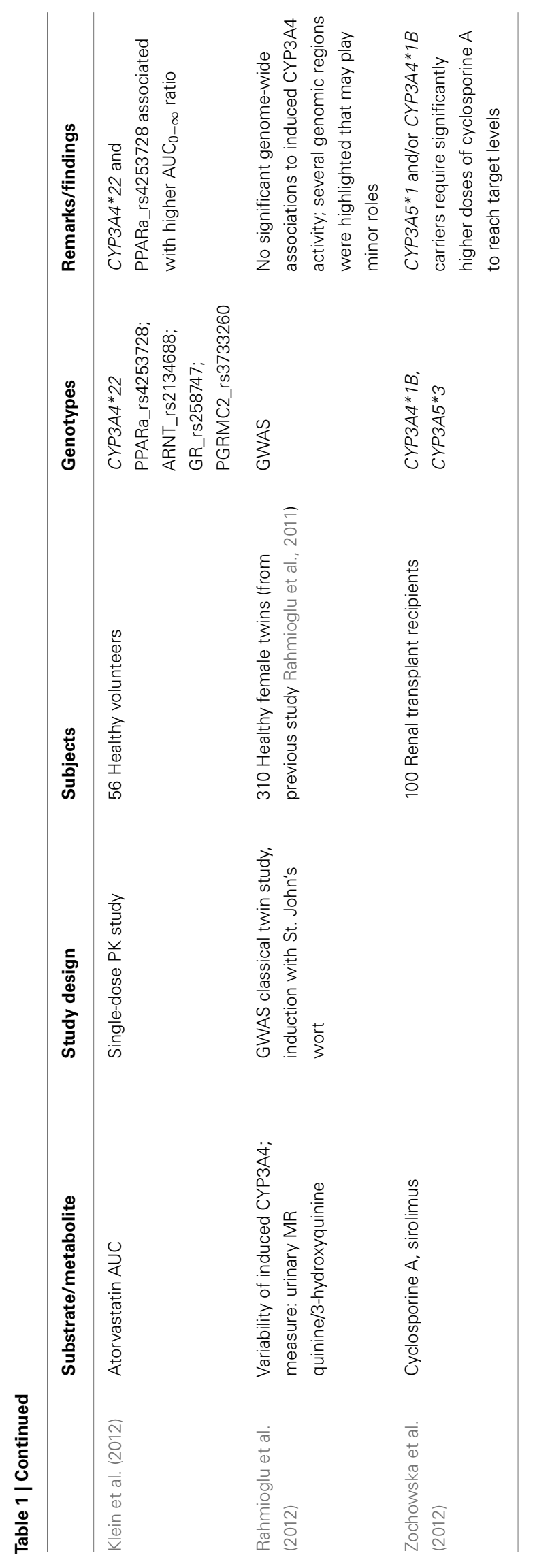

treatment. It was shown that several individuals with elevated efavirenz plasma concentrations could be predicted when rare variants were considered together with the common low-expressor *6-allele (Rotger et al., 2007). Taking this into account, the knowledge on genetic variability of ADME (Absorption Distribution Metabolism Excretion) genes including CYP3A4 in diverse populations will profit enormously from 1000 Genomes and new candidate SNPs influencing CYP3A4 expression and activity will certainly be discovered, although prediction or experimental testing of functional impact of the many novel variants pose a challenging task.

\section{GENES INFLUENCING CYP3A4 PHENOTYPE OUTSIDE THE CYP3A LOCUS}

Regulation of CYP3A4 phenotype expression is enormously complex including influences from networks of nuclear receptors and other transcription factors (Pascussi et al., 2008), hormonal and inflammatory pathways (Aitken et al., 2006), heme and protein synthesis, and degradation pathways, as well as components of monooxygenase complexes and their interaction partners (see in Figure 2). Potentially influential polymorphisms in these genes on CYP3A4 expression have been studied only in recent years by single gene or pathway-directed approaches.

NADPH:cytochrome P450 oxidoreductase (POR) is a microsomal flavoprotein and an obligatory electron donator in the microsomal P450 monooxygenase reaction. In contrast to the multiplicity of CYPs, mammals have only a single POR gene. In humans the gene is located on chromosome 7q11.2 and spans about $72 \mathrm{~kb}$, coding for a 680 amino acid protein. Complete deletion of the por gene in mouse is embryonically lethal most likely due to deficient adrenocortical steroidogenesis (Shen et al., 2002; Otto et al., 2003). In contrast, liver-specific por knockout leads to phenotypically and reproductively normal mice that accumulate hepatic lipids and have a drastically diminished capacity for hepatic drug metabolism (Gu et al., 2003; Finn et al., 2007).

The amount of POR in human liver is stoichiometrically $\sim 5$ - to 10-fold lower compared to the microsomal CYP pool, and hepatic POR levels are correlated to several P450 monooxygenase activities, suggesting that it represents a limiting factor (Huang et al., 2008a; Gomes et al., 2009). Functional polymorphisms in POR should thus be expected to influence CYP activity. In recent years rare POR missense mutations in humans were discovered that impair POR function and cause disordered steroidogenesis, ambiguous genitalia, and Antley-Bixler syndrome (Flück et al., 2004; Flück and Pandey, 2011). The CYPalleles website currently lists 41 distinct star-alleles, most of which represent very rare mutations, but common polymorphisms also exist (Huang et al., 2005, 2008a).

In particular the $\mathrm{A} 503 \mathrm{~V}$ variation $\left(\mathrm{POR}^{*} 28\right)$ is common with frequencies ranging from 19 to $37 \%$ in all major ethnicities. In recombinant systems the variant retained $>50 \%$ of the wild type activity toward several CYPs (Huang et al., 2008b; Sandee et al., 2010) and CYP3A4 activity was influenced in a substratedependent way (Agrawal et al., 2010). In an in vivo study it was found that $P O R^{*} 28$ TT genotype was associated with a 1.6-fold increase in CYP3A midazolam 1'-hydroxylase activity compared with $P O R^{*} 28 \mathrm{C}$ carriers, a finding that could be replicated in an 
Table 2 | Overview of databases providing valuable SNP/mutation data.

\begin{tabular}{|c|c|c|}
\hline Name & link & Info $^{a}$ \\
\hline Human CYPallele & http://www.cypalleles.ki.se/ & Overview on functional SNPs in CYP \\
\hline PharmGKB & http://www.pharmgkb.org/ & $\begin{array}{l}\text { Summarizing gene-drug-disease relationship, clinical PGx, } \\
\text { PGx research, and many more; referring to dbSNP_build137 }\end{array}$ \\
\hline $\mathrm{dbSNP}$ & http://www.ncbi.nlm.nih.gov/projects/SNP/ & $\mathrm{NCBI}$ database \\
\hline 1000 Genomes Project & http://browser.1000genomes.org/index.html & NGS project \\
\hline SNPedia & http://www.snpedia.com/index.php/SNPedia & $\begin{array}{l}\text { Provides information on the platforms including specific } \\
\text { polymorphisms }\end{array}$ \\
\hline MutDB (Mooney Lab) & http://www.mutdb.org/cgi-bin/mutdb.pl & $\begin{array}{l}\text { Data from dbSNP (NCBI) and Swiss-Prot, includes SIFT } \\
\text { prediction for amino acid variants }\end{array}$ \\
\hline $\begin{array}{l}\text { Database of genomic } \\
\text { variation (DGV) }\end{array}$ & http://projects.tcag.ca/variation/ & $\begin{array}{l}\text { All SNPs from dbSNP, overview on structural genomic } \\
\text { variations (CNV, segmental duplications/deletions, InDels) }\end{array}$ \\
\hline GeneCards & http://www.genecards.org/index.shtml & $\begin{array}{l}\text { dbSNP information in a compact overview with graphically } \\
\text { illustrated frequencies }\end{array}$ \\
\hline SNAP & http://www.broadinstitute.org/mpg/snap/ & Displaying linkage graphically ( $R^{2}$ measure) \\
\hline
\end{tabular}

${ }^{a}$ PGX, pharmacogenomics; Swiss-Prot, manually annotated and reviewed protein knowledge base at the Swiss Institute of Bioinformatics Resource portal ExPASY; NGS, next generation sequencing; SIFT, "sorting intolerant from tolerant" protein variant prediction tool.

independent cohort (Oneda et al., 2009). Similarly, in a cohort of allograft recipients under tacrolimus therapy, $P O R^{*} 28 \mathrm{~T}$-allele carriers had significantly higher tacrolimus dose requirements compared to non-carriers but only if they were genotypic CYP3A5 expressors (i.e., presence of at least one CYP3A ${ }^{*} 1$ allele; De Jonge et al., 2011). Thus, the effect of this common $P O R$ variant appears to depend on the CYP isozyme as well as the substrate.

Numerous additional genetic $P O R$ variants have been identified (Hart et al., 2008; Huang et al., 2008a). With regard to CYP3A4, several variants were described to affect its function in liver, in vitro or in vivo. A multivariate analysis in human liver microsomes identified three intronic POR variants that affected several CYP activities and that accounted for $60 \%$ of the microsomal atorvastatin hydroxylase variability, in concert with the donor's sex (Gomes et al., 2009). Chen et al. analyzed six full length protein variants for their impact on CYP3A4-mediated testosterone hydroxylation and on CYP2B6-mediated bupropion hydroxylation in a recombinant system. Several $P O R$ variants showed markedly differential effects on both activities (Chen et al., 2012). In vivo, reduction in hepatic drug metabolizing CYP3A4 activities caused by POR mutations was also described in patients with disordered steroid metabolism (Flück et al., 2010). Taken together these recent advances indicate that $P O R$ variants are a complex but potentially relevant source of genetic variation for CYP3A-related drug oxidation phenotypes (Miller et al., 2011).

The xenosensors pregnane X-receptor (PXR, NR112) and constitutive androstane receptor (CAR, NR1I3) are important transcription factors in the regulatory network of CYP3A4 constitutive and inducible expression. Both genes are polymorphic and genetic variants have been studied for impact on CYP3A4 transcription (Lamba et al., 2005). Despite existence of numerous alternative transcripts, naturally occurring functional polymorphisms of CAR that contribute to CYP3A4 phenotypic expression are not well documented. In contrast, the functional impact of genetic PXR variants has been studied more thoroughly. For example, the protein variants V140M, D163G, and A370T, discovered in an exon sequence screening of PXR gene in DNA samples of several ethnicities, were shown to exhibit altered basal or induced transactivation activity of CYP3A4 promoter using recombinant variant expression and promoter-reporter constructs (Hustert et al., 2001b). Resequencing analysis of 46 liver tissue samples of Caucasian origin and hepatocytes identified SNPs in the PXR promoter and intron 1 associated with CYP3A4 mRNA expression, mainly due to destruction of putative transcription factor binding sites within the regulatory region of $P X R$ by polymorphisms in strong linkage (Lamba et al., 2008). Moreover, the $P X R^{*} 1 B$ haplotype, which is tagged by the SNPs $2654 \mathrm{~T}>\mathrm{C}$ and IVS6-17C $>$ T, was related to doxorubicin clearance in Asian breast cancer patients (Sandanaraj et al., 2008). Further studies analyzing patient cohorts under fosamprenavir/lopinavir or artemisinin treatment gave additional hints to some PXR variants that may affect inducibility of CYP3A4 phenotype expression (Svärd et al., 2010; Piedade et al., 2012). The occurrence of two SNPs in the $3^{\prime}$ UTR region of $P X R$, rs3732359 and rs3732360, has been shown to be associated with altered midazolam $1^{\prime}$-hydroxylation in a liver bank and with more pronounced effect in midazolam clearance of healthy volunteers of African American descent (Oleson et al., 2010). Two recent studies included $P X R$ polymorphisms in their pathway targeted pharmacogenetic approach on variable CYP3A4 expression in liver samples (Lamba et al., 2010; Klein et al., 2012). Although in the former study PXR rs1523130 was significantly associated with CYP3A4 mRNA expression by univariate analysis 

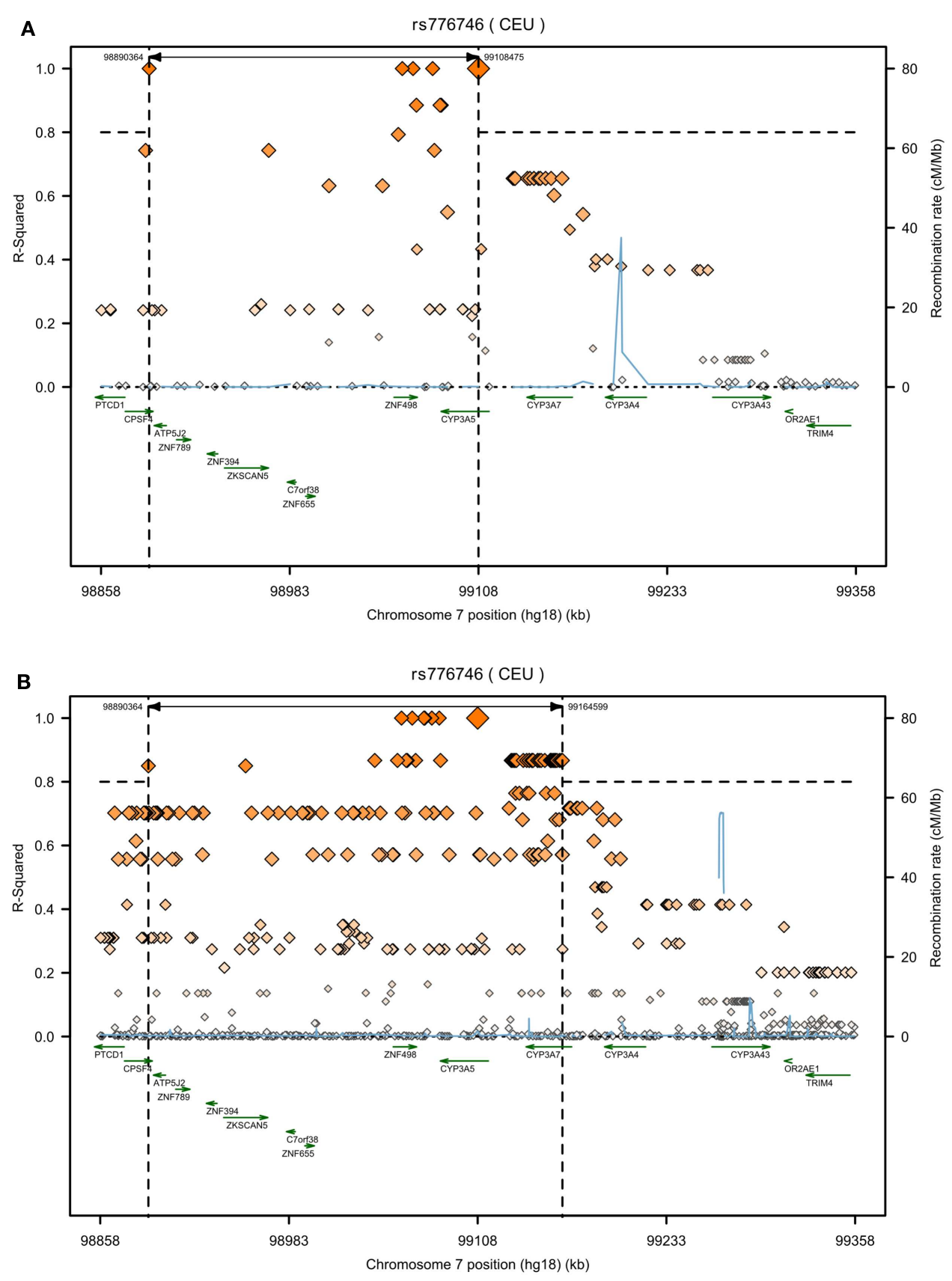

FIGURE 1 | Increase of SNP data information by the 1000 Genomes Project within the CYP3A locus. LD-plots are generated for rs776746 using SNAP (http://www.broadinstitute.org/mpg/snap/ldplot.php); $250 \mathrm{~kb}$ region up- and downstream of the target SNP; genes are marked by green arrows, SNPs are shown with their $R^{2}$-square values calculated versus the target SNP rs776746 (red squares) and recombination rates are given in $\mathrm{cM} / \mathrm{Mb}$ (blue line); dashed lines mark the threshold for strong linkage $R^{2}=0.8$ (horizontal) and the corresponding region of linked SNPs (vertical); (A) HapMap3 Release 2, CEU (B) 1000 Genomes Pilot 1, CEU. and in the multivariate model, the latter study did not document a significant contribution of PXR SNPs in univariate as well as in multivariate statistical models on mRNA, protein or activity. In summary, contribution of PXR variants to CYP3A4 expression remains controversial and may be limited and dependent on the population studied.
Based on the observation that CYP3A4 and the multi-drug resistance protein P-glycoprotein [P-gp, product of the MDR1 $(A B C B 1)$ gene] display largely overlapping substrate selectivity (Wacher et al., 1995; Patel and Mitra, 2001; Pal and Mitra, 2006), it has been hypothesized that changes in P-gp expression may influence the intracellular concentration of endogenous or 
Table 3 | CYP3A4 coding SNPs provided by the 1000 Genomes Project (selected are the SNPs for the major transcript ENST00000336411 from http://browser.1000genomes.org/Homo_sapiens/Search/Results?site=ensembl\&q=cyp3a4) accessedSeptember 2012.

\begin{tabular}{|c|c|c|c|c|c|c|c|c|c|c|}
\hline ID & Chr7: bp & Alleles & Class & Source & $\begin{array}{l}\text { CYPallele } \\
\text { (activity) }^{\text {a }}\end{array}$ & Type & $\begin{array}{l}\text { Amino } \\
\text { acid }\end{array}$ & $\begin{array}{l}\text { AA } \\
\text { co-ordinate }^{b}\end{array}$ & SIFT & PolyPhen \\
\hline rs12721634 & 99381661 & $A / G$ & SNP & $\mathrm{dbSNP}$ & *14 & $\mathrm{nsc}$ & $\mathrm{L} / \mathrm{P}$ & $15(2)$ & Deleterious & Probably D \\
\hline rs56324128 & 99375702 & $\mathrm{C} / \mathrm{T}$ & SNP & $\mathrm{dbSNP}$ & $* 7$ & nsc, ss & G/D & $56(2)$ & Deleterious & Probably D \\
\hline rs59418896 & 99375666 & $\mathrm{~T} / \mathrm{C}$ & SNP & $\mathrm{dbSNP}$ & & nsc & $\mathrm{Y} / \mathrm{C}$ & $68(2)$ & Deleterious & Probably D \\
\hline rs3091339 & 99370245 & $\mathrm{~T} / \mathrm{C}$ & SNP & $\mathrm{dbSNP}$ & & nsc & $\mathrm{K} / \mathrm{E}$ & $96(1)$ & Deleterious & Probably D \\
\hline rs72552799 & 99367788 & $\mathrm{C} / \mathrm{T}$ & SNP & $\mathrm{dbSNP}, 1000 \mathrm{G}$ & *8 (decr) & nsc & $\mathrm{R} / \mathrm{Q}$ & $130(2)$ & Deleterious & Probably D \\
\hline rs4987161 & 99366081 & $A / G$ & SNP & $\mathrm{dbSNP}$ & ${ }^{*} 17$ (decr) & nsc & $\mathrm{F} / \mathrm{S}$ & $189(2)$ & Deleterious & Probably D \\
\hline rs139541290 & 99366075 & $A / G$ & SNP & $\mathrm{dbSNP}$ & & nsc & V/A & $191(2)$ & Deleterious & Probably D \\
\hline rs55901263 & 99365994 & $\mathrm{G} / \mathrm{C}$ & SNP & $\mathrm{dbSNP}$ & $*^{*}$ & nsc & $P / R$ & $218(2)$ & Deleterious & Probably D \\
\hline rs75726589 & 99364854 & $A / G$ & SNP & dbSNP & & nsc & $\mathrm{L} / \mathrm{P}$ & $233(2)$ & Deleterious & Probably D \\
\hline rs67784355 & 99359829 & $\mathrm{G} / \mathrm{A}$ & SNP & $\mathrm{dbSNP}, 1000 \mathrm{G}$ & ${ }^{*} 11$ (decr) & nsc & $\mathrm{T} / \mathrm{M}$ & $363(2)$ & Deleterious & Probably D \\
\hline rs113716682 & 99359715 & $A / G$ & SNP & $\mathrm{dbSNP}$ & & nsc & $\mathrm{L} / \mathrm{P}$ & $401(2)$ & Deleterious & Probably D \\
\hline rs143966082 & 99359710 & $\mathrm{G} / \mathrm{A}$ & SNP & $\mathrm{dbSNP}$ & & nsc & $\mathrm{R} / \mathrm{C}$ & 403 (1) & Deleterious & Probably D \\
\hline rs72552797 & 99359685 & $\mathrm{G} / \mathrm{A}$ & SNP & $\mathrm{dbSNP}$ & & $\mathrm{nsc}$ & $\mathrm{P} / \mathrm{L}$ & $411(2)$ & Deleterious & Probably D \\
\hline rs4986909 & 99359670 & $\mathrm{G} / \mathrm{A}$ & SNP & $\mathrm{dbSNP}$ & *13 (decr) & nsc & $\mathrm{P} / \mathrm{L}$ & $416(2)$ & Deleterious & Probably D \\
\hline rs4986910 & 99358524 & $A / G$ & SNP & $\mathrm{dbSNP}$ & ${ }^{*} 3$ & nsc & $\mathrm{M} / \mathrm{T}$ & $445(2)$ & Deleterious & Probably D \\
\hline rs72552796 & 99358521 & $\mathrm{C} / \mathrm{T}$ & SNP & $\mathrm{dbSNP}$ & & nsc & $\mathrm{R} / \mathrm{K}$ & $446(2)$ & Deleterious & Probably D \\
\hline rs71583803 & 99358470 & $\mathrm{~A} / \mathrm{C}$ & SNP & $\mathrm{dbSNP}$ & & nsc & $\mathrm{F} / \mathrm{C}$ & $463(2)$ & Deleterious & Probably D \\
\hline rs78764657 & 99377692 & $\mathrm{G} / \mathrm{C}$ & SNP & $\mathrm{dbSNP}$ & & nsc & $H / D$ & $30(1)$ & Deleterious & Possibly D \\
\hline rs140422742 & 99375669 & $\mathrm{~T} / \mathrm{C}$ & SNP & $\mathrm{dbSNP}$ & & nsc & $\mathrm{K} / \mathrm{R}$ & $67(2)$ & Deleterious & Possibly D \\
\hline rs57409622 & 99367428 & $\mathrm{G} / \mathrm{A}$ & SNP & $\mathrm{dbSNP}$ & & nsc & $\mathrm{R} / \mathrm{W}$ & $162(1)$ & Deleterious & Possibly D \\
\hline rs149870259 & 99358596 & $\mathrm{~T} / \mathrm{C}$ & SNP & $\mathrm{dbSNP}$ & & nsc & $\mathrm{K} / \mathrm{R}$ & $421(2)$ & Deleterious & Benign \\
\hline rs28371760 & 99358498 & $A /-$ & del & $\mathrm{dbSNP}$ & & $\mathrm{nsc}$, fs & $L / I$ & $454(1)$ & Deleterious & Benign \\
\hline rs150559030 & 99358488 & $A / T$ & SNP & $\mathrm{dbSNP}$ & & nsc & $\mathrm{I} / \mathrm{N}$ & $457(2)$ & Deleterious & Benign \\
\hline rs12721627 & 99366093 & $\mathrm{G} / \mathrm{C}$ & SNP & $\mathrm{dbSNP}$ & *16 (decr) & nsc & $T / S$ & $185(2)$ & Tolerated & Possibly D \\
\hline rs55785340 & 99365983 & $A / G$ & SNP & $\mathrm{dbSNP}$ & ${ }^{*} 2$ & nsc & $S / P$ & $222(1)$ & Tolerated & Possibly D \\
\hline COSM35658 & 99381689 & $\mathrm{C} / \mathrm{T}$ & Somatic_SNV & cosmic & & nsc & $\mathrm{D} / \mathrm{N}$ & $6(1)$ & Tolerated & Benign \\
\hline rs140355261 & 99381687 & $\mathrm{G} / \mathrm{C}$ & SNP & $\mathrm{dbSNP}$ & & nsc & $\mathrm{D} / \mathrm{E}$ & $6(3)$ & Tolerated & Benign \\
\hline COSM42989 & 99381680 & $\mathrm{~T} / \mathrm{C}$ & Somatic_SNV & COSMIC & & nsc & $\mathrm{M} N$ & $9(1)$ & Tolerated & Benign \\
\hline rs55951658 & 99367825 & $\mathrm{~T} / \mathrm{C}$ & SNP & $\mathrm{dbSNP}, 1000 \mathrm{G}$ & $* 4$ & nsc & IN & $118(1)$ & Tolerated & Benign \\
\hline rs147752776 & 99367818 & $A / G$ & SNP & $\mathrm{dbSNP}$ & & nsc & $\mathrm{I} / \mathrm{T}$ & $120(2)$ & Tolerated & Benign \\
\hline rs4986907 & 99367427 & $\mathrm{C} / \mathrm{T}$ & SNP & $\mathrm{dbSNP}$ & *15 & nsc & $\mathrm{R} / \mathrm{Q}$ & $162(2)$ & Tolerated & Benign \\
\hline rs72552798 & 99367404 & $\mathrm{C} / \mathrm{T}$ & SNP & dbSNP & $*^{*} 9$ & nsc & $\mathrm{V} / \mathrm{I}$ & $170(1)$ & Tolerated & Benign \\
\hline rs3208361 & 99366070 & $\mathrm{~T} / \mathrm{C}$ & SNP & dbSNP & & nsc & $\mathrm{I} N$ & $193(1)$ & Tolerated & Benign \\
\hline rs113667357 & 99366047 & $\mathrm{~T} / \mathrm{A} / \mathrm{C}$ & SNP & $\mathrm{dbSNP}$ & & nsc & $\mathrm{Q} / \mathrm{H}$ & 200 (3) & Tolerated & Benign \\
\hline rs181612501 & 99365992 & $A / G$ & SNP & $1000 \mathrm{G}$ & & nsc & $F / L$ & 219 (1) & Tolerated & Benign \\
\hline rs3208363 & 99364798 & $\mathrm{~A} / \mathrm{C}$ & SNP & $\mathrm{dbSNP}$ & & nsc & $S / A$ & $252(1)$ & Tolerated & Benign \\
\hline
\end{tabular}


Table 3 | Continued

\begin{tabular}{|c|c|c|c|c|c|c|c|c|c|c|}
\hline ID & Chr7: bp & Alleles & Class & Source & $\begin{array}{l}\text { CYPallele } \\
\text { (activity) }^{a}\end{array}$ & Type & $\begin{array}{l}\text { Amino } \\
\text { acid }\end{array}$ & $\begin{array}{l}\text { AA } \\
\text { co-ordinate }{ }^{b}\end{array}$ & SIFT & PolyPhen \\
\hline $\begin{array}{l}\text { 1000GENOMES_ } \\
\text { 7_99364768 }\end{array}$ & 99364768 & $\mathrm{C} / \mathrm{T}$ & SNP & $1000 G$ & & $\mathrm{nsc}$ & $E / K$ & $262(1)$ & Tolerated & Benign \\
\hline rs28371759 & 99361626 & $A / G$ & SNP & $\mathrm{dbSNP}$ & *18 & nsc & $\mathrm{L} / \mathrm{P}$ & $293(2)$ & Tolerated & Benign \\
\hline rs138675831 & 99361618 & $\mathrm{C} / \mathrm{T}$ & SNP & $\mathrm{dbSNP}$ & & nsc & $\mathrm{V} / \mathrm{M}$ & $296(1)$ & Tolerated & Benign \\
\hline $\begin{array}{l}\text { 1000GENOMES_ } \\
\text { 7_99361606 }\end{array}$ & 99361606 & $\mathrm{~T} / \mathrm{C}$ & SNP & $1000 G$ & & $\mathrm{nsc}$ & IN & $300(1)$ & Tolerated & Benign \\
\hline rs10250778 & 99359871 & $\mathrm{G} / \mathrm{T}$ & SNP & $\mathrm{dbSNP}$ & & nsc & $\mathrm{T} / \mathrm{N}$ & $349(2)$ & Tolerated & Benign \\
\hline rs145669559 & 99359812 & $\mathrm{~T} / \mathrm{C}$ & SNP & $\mathrm{dbSNP}$ & & nsc & IN & 369 (1) & Tolerated & Benign \\
\hline rs12721629 & 99359800 & $\mathrm{G} / \mathrm{A}$ & SNP & dbSNP & *12 (decr?) & nsc & $L / F$ & $373(1)$ & Tolerated & Benign \\
\hline rs142425279 & 99359734 & $\mathrm{~T} / \mathrm{C}$ & SNP & dbSNP & & $\mathrm{nsc}$ & MN & $395(1)$ & Tolerated & Benign \\
\hline rs139109027 & 99358581 & $\mathrm{~T} / \mathrm{C}$ & SNP & dbSNP & & $\mathrm{nsc}$ & $\mathrm{N} / \mathrm{S}$ & $426(2)$ & Tolerated & Benign \\
\hline rs1041988 & 99358566 & $A / G$ & SNP & dbSNP & & $\mathrm{nsc}$ & $\mathrm{I} / \mathrm{T}$ & $431(2)$ & Tolerated & Benign \\
\hline rs4986913 & 99358459 & $\mathrm{G} / \mathrm{A}$ & SNP & dbSNP & *19 & $\mathrm{nsc}$ & $\mathrm{P} / \mathrm{S}$ & 467 (1) & Tolerated & Benign \\
\hline rs181210913 & 99358450 & $\mathrm{C} / \mathrm{T}$ & SNP & $1000 \mathrm{G}$ & & $\mathrm{nsc}$ & $E / K$ & $470(1)$ & Tolerated & Benign \\
\hline rs138105638 & 99364063 & $\mathrm{G} / \mathrm{A}$ & SNP & dbSNP & & Stop & $\mathrm{R} /{ }^{*}$ & $268(1)$ & - & - \\
\hline rs34784390 & $\begin{array}{l}99364036- \\
99364035\end{array}$ & $-\pi$ & ins & $\mathrm{dbSNP}$ & & fs & & $277(2)$ & - & - \\
\hline rs4646438 & $\begin{array}{l}99364035- \\
99364034\end{array}$ & $-\pi$ & ins & $\mathrm{dbSNP}$ & ${ }^{*} 6$ & fs & & 277 (3) & - & - \\
\hline rs72552795 & $\begin{array}{l}99358466- \\
99358465\end{array}$ & $-/ G$ & ins & dbSNP & & fs & & $465(1)$ & - & - \\
\hline rs67666821 & $\begin{array}{l}99355807- \\
99355806\end{array}$ & $-\Pi$ & ins & $\mathrm{dbSNP}$ & *20 (no) & fs & & $488(1)$ & - & - \\
\hline
\end{tabular}

${ }^{a}$ Derived from http://www.cypalleles. ki.se/; Information not provided by 1000 Genomes.

${ }^{b}$ Number corresponds to the codon, variant nucleotide of the triplet is given brackets; nsc, non-synonymous coding; fs, frameshift; $D$, damaging.

exogenous substances that potentially lead to CYP3A4 induction, thus contributing to CYP3A4 expression differences (Lamba et al., 2006). Although data supporting this hypothesis have been reported in one human liver association study (Lamba et al., 2010), they were not reproduced in another study (Klein et al., 2012).

In search for additional influential genes, Lamba et al. (2010) phenotyped 128 livers by quantitative real-time PCR for expression of CYP3A genes and identified a functional CCT-repeat polymorphism in the FoxA2 ( $H N F 3 \alpha$ ) gene to be associated with higher expression of FoxA2 mRNA and its target genes PXR and CYP3A4.

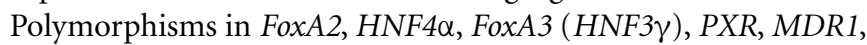
and the CYP3A4 promoter together with sex explained $24.6 \%$ of the variation in hepatic CYP3A4 mRNA expression. However the study lacked information on the relevance of these variations for CYP3A4 protein and activity.

More recently, we carried out extensive candidate gene approaches on 150 Caucasian liver samples phenotyped for CYP1A2 and CYP3A4 mRNA and protein levels, as well as enzyme activity (Klein et al., 2010, 2012). With respect to CYP3A4, we identified SNPs in the Ah-receptor nuclear translocator (ARNT), glucocorticoid receptor $(G R)$, progesterone receptor membrane component 2 (PGRMC2), and peroxisome proliferator-activated receptor alpha (PPARA) to be consistently associated with CYP3A4 phenotype in human liver in the multivariate analysis. Validation in an atorvastatin-treated volunteer cohort confirmed decreased atorvastatin-2-hydroxylation in carriers of PPARA SNP rs4253728. Moreover, homozygous carriers of the variant had reduced PPAR $\alpha$ protein expression in liver, and shRNAmediated PPARA gene knock-down in primary human hepatocytes decreased mRNA expression levels of CYP3A4 by more than $50 \%$. Multivariate analysis revealed that two linked PPARA SNPs alone explained $\sim 8-9 \%$ of the atorvastatin hydroxylase activity variation, whereas all genetic and non-genetic factors together accounted for $\sim 33 \%$ of atorvastatin 2-hydroxylase variation in this liver cohort (Klein et al., 2012). This result was somewhat unexpected, because PPAR $\alpha$ had so far not been considered as a major regulator of $C Y P 3 A 4$, although inducing effects by fibrates had been noted before in human, but not mouse primary hepatocytes (Prueksaritanont et al., 2005; Rakhshandehroo et al., 2009). The interesting question of course is, whether CYP3A4 is a direct target of PPAR $\alpha$ or whether indirect regulation, e.g., via nuclear receptor crosstalk resulting in downregulation of PXR (Aouabdi et al., 2006; Takagi et al., 2008) is the causative mechanism. Recent data from our group suggest, however, that PPAR $\alpha$ indeed binds to several non-consensus PPAR $\alpha$-response elements (PPREs) in the CYP3A4 promoter to activate transcription in a ligand-dependent manner (Thomas et al., 2013). Because PPAR $\alpha$ is a master regulator of lipid homeostasis and energy balance, these results indicate a novel connection between endogenous and xenobiotic metabolism. 


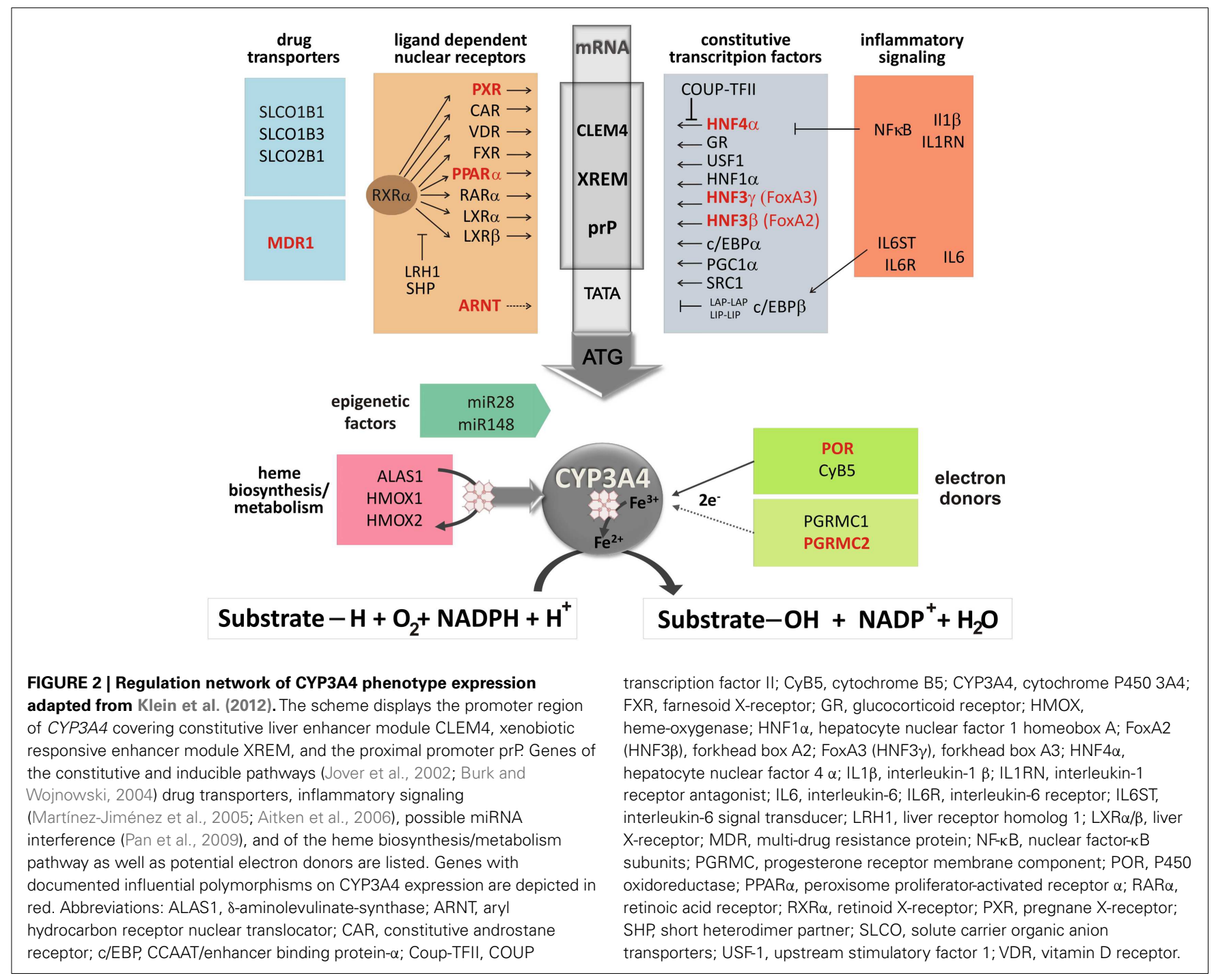

\section{NEW ASPECTS/OUTLOOK}

Several genome-wide association studies with a total number of over 1000 human liver samples identified a large number of novel expression quantitative trait loci (eQTL) for numerous liverexpressed genes (Schadt et al., 2008; Yang et al., 2010; Innocenti et al., 2011; Schröder et al., 2013). Although the advantage of this approach is the unbiased way of investigation, results were rather disappointing with respect to CYPs, probably due to lack of statistical power. Thus, mainly polymorphisms in CYP2D6 and CYP $3 A 5$ were reproduced in these studies (Schadt et al., 2008; Schröder et al., 2013). Building up on one eQTL study, Yang et al. used the genome-wide SNP data of 466 livers to search for associations with enzyme activities determined for 9 CYPs (i.e., activity- or aQTLs). A total of 54 SNPs influencing 8 CYP activities were identified, of which 30 influenced CYP2D6 in cis (i.e., SNPs were located within $\pm 1 \mathrm{Mb}$ of the CYP2D6 gene), whereas all remaining 24 SNPs were described as trans-acting elements, and only one of these (rs12041966 located on chromosome 1) influenced testosterone hydroxylation (Yang et al., 2010). Unfortunately, functional

annotation of the trans-acting SNPs was not possible in this study, and these results thus await further experimental confirmation.

A further level of potential importance, which has not yet been explored in terms of genetic variability concerns the influence of epigenetic processes on pharmacologically relevant genes and drug response (Gomez and Ingelman-Sundberg, 2009). SNPs in DNA methylation regions or miRNAs and miRNA binding sites, as well as miRNA copy number variations may influence target gene expression (Schmeier et al., 2011). Thus, CYP3A4 expression was shown to be directly regulated by miRNAs but can also be influenced indirectly by miRNA regulation of transcriptional regulators such as PXR and VDR (Pan et al., 2009). However, polymorphic variation within this regulatory pathway has not yet been analyzed. Furthermore, additionally to regulatory polymorphisms (rSNPs) affecting transcription, structural RNA polymorphisms (termed srSNPs) are suggested to influence RNA function (splicing, turnover, translation) and to display promising biomarkers (Sadee et al., 2011; Lee et al., 2012). 
The ENCODE project (ENCyclopedia Of DNA Elements) ${ }^{5}$ systematically analyzes functional DNA elements in the human genome (e.g., binding data for more than 100 transcription factors, DNAse sensitive sites, methylation, chromatin interaction, and genotyping from multiple cell types) and may provide new hypotheses on functional consequences of SNPs located especially in non-coding DNA-regions (Bernstein et al., 2012; Gerstein et al., 2012; Yip et al., 2012).

In conclusion, the predictive power of currently known genetic polymorphisms with relevance for CYP3A4 in vivo phenotype is still far away from the expected $60-80 \%$ of genetic determination. The use of next generation sequencing approaches for the identification of causal variants in CYP3A4 as well as the numerous genes of its many influential pathways may lead to the identification of many more rare and common DNA variants that together account for a sizeable fraction of this variability. The examples of

${ }^{5} \mathrm{http} / / /$ genome.ucsc.edu/ENCODE/

\section{REFERENCES}

Agrawal, V., Choi, J. H., Giacomini, K. M., and Miller, W. L. (2010). Substrate-specific modulation of CYP3A4 activity by genetic variants of cytochrome $\mathrm{P} 450$ oxidoreductase. Pharmacogenet. Genomics 20, 611-618.

Aitken, A. E., Richardson, T. A., and Morgan, E. T. (2006). Regulation of drug-metabolizing enzymes and transporters in inflammation. Annu. Rev. Pharmacol. Toxicol. 46, 123-149.

Akiyoshi, T., Saito, T., Murase, S., Miyazaki, M., Murayama, N., Yamazaki, H., et al. (2011). Comparison of the inhibitory profiles of itraconazole and cimetidine in cytochrome P450 3A4 genetic variants. Drug Metab. Dispos. 39, 724-728.

Amirimani, B., Ning, B., Deitz, A. C., Weber, B. L., Kadlubar, F. F., and Rebbeck, T. R. (2003). Increased transcriptional activity of the CYP3A $4 * 1 \mathrm{~B}$ promoter variant. Environ. Mol. Mutagen. 42, 299-305.

Aouabdi, S., Gibson, G., and Plant, N. (2006). Transcriptional regulation of the PXR gene: identification and characterization of a functional peroxisome proliferator-activated receptor alpha binding site within the proximal promoter of PXR. Drug Metab. Dispos. 34, 138-144.

Ball, S. E., Scatina, J., Kao, J., Ferron, G. M., Fruncillo, R., Mayer, P., et al. (1999). Population distribution and effects on drug metabolism of a genetic variant in the 5' promoter region of CYP3A4. Clin. Pharmacol. Ther. 66, 288-294.
Bernstein, B. E., Birney, E., Dunham, I., Green, E. D., Gunter, C., and Snyder, M. (2012). An integrated encyclopedia of DNA elements in the human genome. Nature 489, 57-74.

Bodin, K., Lindbom, U., and Diczfalusy, U. (2005). Novel pathways of bile acid metabolism involving CYP3A4. Biochim. Biophys. Acta 1687, 84-93.

Bu, H.-Z. (2006). A literature review of enzyme kinetic parameters for CYP3A4-mediated metabolic reactions of 113 drugs in human liver microsomes: structure-kinetics relationship assessment. Curr. Drug Metab. 7, 231-249.

Burk, O., and Wojnowski, L. (2004). Cytochrome P450 3A and their regulation. Naunyn Schmiedebergs Arch. Pharmacol. 369, 105-124.

Chen, C.-H., Wang, S.-C., Tsou, H.H., Ho, I.-K., Tian, J.-N., Yu, C.J., et al. (2011). Genetic polymorphisms in CYP3A4 are associated with withdrawal symptoms and adverse reactions in methadone maintenance patients. Pharmacogenomics 12, 1397-1406.

Chen, X., Pan, L. Q., Naranmandura, H., Zeng, S., and Chen, S. Q. (2012). Influence of various polymorphic variants of cytochrome $\mathrm{P} 450$ oxidoreductase (POR) on drug metabolic activity of CYP3A4 and CYP2B6. PLoS ONE 7:e38495. doi:10.1371/journal.pone.0038495

Chen, X., Wang, H., Zhou, G., Zhang, X., Dong, X., Zhi, L., et al. (2009). Molecular population genetics of human CYP3A locus: signatures of positive selection and implications for

POR and PPARA demonstrate that CYP3A4 variability is at least in part determined by polymorphisms in genes outside the CYP3A4 locus. However, investigating and validating trans-acting factors is much more difficult due to the more indirect nature of interaction which is more likely to be masked by covariates, thus necessitating larger studies, in vitro or in vivo. In addition, mathematical algorithms are needed to combine many genetic variants, some of which contribute only small fractions to the total variability, into practically useful signatures for application on clinical studies and individualized medicine.

\section{ACKNOWLEDGMENTS}

Work in the authors' laboratory was supported by the German Federal Ministry of Education and Research (Virtual Liver Network grant 0315755), the 7FP EU Initial Training Network program,FightingDrugFailure' (GA-2009238132), and by the Robert-Bosch Foundation, Stuttgart, Germany.

evolutionary environmental medicine. Environ. Health Perspect. 117, 1541-1548.

Chen, Y.-C., Gotzkowsky, S. K., Nafziger, A. N., Kulawy, R. W., Rocci, M. L., Bertino, J. S., et al. (2006). Poor correlation between 6 $\beta$-hydroxycortisol:cortisol molar ratios and midazolam clearance as measure of hepatic CYP3A activity. Br. J. Clin. Pharmacol. 62, 187-195.

Daly, A. K. (2006). Significance of the minor cytochrome $\mathrm{P} 4503 \mathrm{~A}$ isoforms. Clin. Pharmacokinet. 45, 13-31.

De Jonge, H., Metalidis, C., Naesens, M., Lambrechts, D., and Kuypers, D. R. J. (2011). The P450 oxidoreductase $* 28 \mathrm{SNP}$ is associated with low initial tacrolimus exposure and increased dose requirements in CYP3A5-expressing renal recipients. Pharmacogenomics 12, 1281-1291.

Diczfalusy, U., Kanebratt, K. P., Bredberg, E., Andersson, T. B., Böttiger,

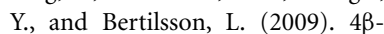
Hydroxycholesterol as an endogenous marker for CYP3A4/5 activity. Stability and half-life of elimination after induction with rifampicin. $B r$. J. Clin. Pharmacol. 67, 38-43.

Diczfalusy, U., Nylén, H., Elander,

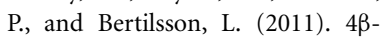
Hydroxycholesterol, an endogenous marker of CYP3A4/5 activity in humans. Br. J. Clin. Pharmacol. 71, 183-189.

Elens, L., Becker, M. L., Haufroid, V., Hofman, A., Visser, L. E., Uitterlinden, A. G., et al. (2011a). Novel CYP3A4 intron 6 single nucleotide polymorphism is associated with simvastatin-mediated cholesterol reduction in the Rotterdam
Study. Pharmacogenet. Genomics 21, 861-866.

Elens, L., Bouamar, R., Hesselink, D. A., Haufroid, V., Van der Heiden, I. P., Van Gelder, T., et al. (2011b). A new functional CYP3A4 intron 6 polymorphism significantly affects tacrolimus pharmacokinetics in kidney transplant recipients. Clin. Chem. 57, 1574-1583.

Elens, L., Van Schaik, R. H., Panin, N., De Meyer, M., Wallemacq, P., Lison, D., et al. (2011c). Effect of a new functional CYP3A4 polymorphism on calcineurin inhibitors' dose requirements and trough blood levels in stable renal transplant patients. Pharmacogenomics 12, 1383-1396.

Elens, L., Bouamar, R., Hesselink, D. A., Haufroid, V., Van Gelder, T., and Van Schaik, R. H. N. (2012). The new CYP3A4 intron $6 \mathrm{C}>\mathrm{T}$ polymorphism $(\mathrm{CYP} 3 \mathrm{~A} 4 * 22)$ is associated with an increased risk of delayed graft function and worse renal function in cyclosporine-treated kidney transplant patients. Pharmacogenet. Genomics 22, 373-380.

Engel, G., Hofmann, U., Heidemann, H., Cosme, J., and Eichelbaum, M. (1996). Antipyrine as a probe for human oxidative drug metabolism: identification of the cytochrome P450 enzymes catalyzing 4-hydroxyantipyrine, 3-hydroxymethylantipyrine, and norantipyrine formation. Clin. Pharmacol. Ther. 59, 613-623.

Evans, W. E., and Relling, M. V. (1999). Pharmacogenomics: translating functional genomics into rational therapeutics. Science 286, $487-491$. 
Feidt, D. M., Klein, K., Hofmann, U., Riedmaier, S., Knobeloch, D., Thasler, W. E., et al. (2010). Profiling induction of cytochrome p450 enzyme activity by statins using a new liquid chromatography-tandem mass spectrometry cocktail assay in human hepatocytes. Drug Metab. Dispos. 38, 1589-1597.

Finn, R. D., McLaren, A. W., Carrie, D., Henderson, C. J., and Wolf, C. R. (2007). Conditional deletion of cytochrome P450 oxidoreductase in the liver and gastrointestinal tract: a new model for studying the functions of the P450 system. J. Pharmacol. Exp. Ther. 322, 40-47.

Floyd, M. D., Gervasini, G., Masica, A. L., Mayo, G., George, A. L. Jr., Bhat, K., et al. (2003). Genotype-phenotype associations for common CYP3A4 and CYP3A5 variants in the basal and induced metabolism of midazolam in European- and AfricanAmerican men and women. Pharmacogenetics 13, 595-606.

Flück, C. E., Mullis, P. E., and Pandey, A. V. (2010). Reduction in hepatic drug metabolizing CYP3A4 activities caused by $\mathrm{P} 450$ oxidoreductase mutations identified in patients with disordered steroid metabolism. Biochem. Biophys. Res. Commun. 401, 149-153.

Flück, C. E., and Pandey, A. V. (2011). Clinical and biochemical consequences of p450 oxidoreductase deficiency. Endocr. Dev. 20, 63-79.

Flück, C. E., Tajima, T., Pandey, A. V., Arlt, W., Okuhara, K., Verge, C. F., et al. (2004). Mutant P450 oxidoreductase causes disordered steroidogenesis with and without Antley-Bixler syndrome. Nat. Genet. 36, 228-230.

Franklin, M. R., Phillips, J. D., and Kushner, J. P. (2000). CYP3A-inducing agents and the ttenuation of uroporphyrin accumulation and excretion in a rat model of porphyria cutanea tarda. Biochem. Pharmacol. 60, 1325-1331.

Fuhr, U., Jetter, A., and Kirchheiner, J. (2007). Appropriate phenotyping procedures for drug metabolizing enzymes and transporters in humans and their simultaneous use in the "cocktail" approach. Clin. Pharmacol. Ther. 81, 270-283.

Galteau, M. M., and Shamsa, F. (2003). Urinary 6beta-hydroxycortisol: a validated test for evaluating drug induction or drug inhibition mediated through CYP3A in humans and in animals. Eur. J. Clin. Pharmacol. 59, 713-733.

Gamazon, E. R., Zhang, W., Huang, R. S., Dolan, M. E., and Cox, N. J. (2009). A pharmacogene database enhanced by the 1000 Genomes Project. Pharmacogenet. Genomics 19, 829-832.

García-Martín, E., Martínez, C., Pizarro, R. M., García-Gamito, F. J., Gullsten, H., Raunio, H., et al. (2002). CYP3A4 variant alleles in white individuals with low CYP3A4 enzyme activity. Clin. Pharmacol. Ther. 71, 196-204.

Gerstein, M. B., Kundaje, A., Hariharan, M., Landt, S. G., Yan, K.-K., Cheng, C., et al. (2012). Architecture of the human regulatory network derived from ENCODE data. Nature 489, 91-100.

Gomes, A. M., Winter, S., Klein, K., Turpeinen, M., Schaeffeler, E., Schwab, M., et al. (2009). Pharmacogenomics of human liver cytochrome P450 oxidoreductase: multifactorial analysis and impact on microsomal drug oxidation. Pharmacogenomics 10, 579-599.

Gomez, A., and Ingelman-Sundberg, M. (2009). Epigenetic and microRNAdependent control of cytochrome P450 expression: a gap between DNA and protein. Pharmacogenomics 10, 1067-1076.

Gu, J., Weng, Y., Zhang, Q.-Y., Cui, H., Behr, M., Wu, L., et al. (2003). Liverspecific deletion of the NADPHcytochrome $\mathrm{P} 450$ reductase gene impact on plasma cholesterol homeostasis and the function and regulation of microsomal cytochrome P450 and heme oxygenase. J. Biol. Chem. 278, 25895-25901.

Hart, S. N., Wang, S., Nakamoto, K., Wesselman, C., Li, Y., and Zhong, X. (2008). Genetic polymorphisms in cytochrome $\mathrm{P} 450$ oxidoreductase influence microsomal P450catalyzed drug metabolism. Pharmacogenet. Genomics 18, 11-24.

He, P., Court, M. H., Greenblatt, D. J., and Von Moltke, L. L. (2005). Genotype-phenotype associations of cytochrome P450 3A4 and $3 A 5$ polymorphism with midazolam clearance in vivo. Clin. Pharmacol. Ther. 77, 373-387.

Hesselink, D. A., Van Gelder, T., Van Schaik, R. H. N., Balk, A. H. M. M., Van der Heiden, I. P., Van Dam, T., et al. (2004). Population pharmacokinetics of cyclosporine in kidney and heart transplant recipients and the influence of ethnicity and genetic polymorphisms in the MDR-1, CYP3A4, and CYP3A5 genes. Clin. Pharmacol. Ther. 76, 545-556.

Hesselink, D. A., Van Schaik, R. H. N., Van der Heiden, I. P., Van der Werf, M., Gregoor, P. J. H. S., Lindemans, J., et al. (2003). Genetic polymorphisms of the CYP3A4, CYP3A5, and MDR-1 genes and pharmacokinetics of the calcineurin inhibitors cyclosporine and tacrolimus. Clin. Pharmacol. Ther. 74, 245-254.

Huang, N., Agrawal, V., Giacomini, K. M., and Miller, W. L. (2008a). Genetics of P450 oxidoreductase: sequence variation in 842 individuals of four ethnicities and activities of 15 missense mutations. Proc. Natl. Acad. Sci. U.S.A. 105, 1733-1738.

Huang, S.-M., Strong, J. M., Zhang, L., Reynolds, K. S., Nallani, S., Temple, R., et al. (2008b). New era in drug interaction evaluation: US Food and Drug Administration update on CYP enzymes, transporters, and the guidance process. J. Clin. Pharmacol. 48, 662-670.

Huang, N., Pandey, A. V., Agrawal, V., Reardon, W., Lapunzina, P. D., Mowat, D., et al. (2005). Diversity and function of mutations in p450 oxidoreductase in patients with Antley-Bixler syndrome and disordered steroidogenesis. Am. J. Hum. Genet. 76, 729-749.

Hustert, E., Haberl, M., Burk, O., Wolbold, R., He, Y. Q., Klein, K., et al. (2001a). The genetic determinants of the CYP3A5 polymorphism. Pharmacogenetics 11, 773-779.

Hustert, E., Zibat, A., Presecan-Siedel, E., Eiselt, R., Mueller, R., Fuß, C., et al. (2001b). Natural protein variants of pregnane $\mathrm{X}$ receptor with altered transactivation activity toward CYP3A4. Drug Metab. Dispos. 29, 1454-1459.

Innocenti, F., Cooper, G. M., Stanaway, I. B., Gamazon, E. R., Smith, J. D., Mirkov, S., et al. (2011). Identification, replication, and functional fine-mapping of expression quantitative trait loci in primary human liver tissue. PLoS Genet. 7:e1002078. doi:10.1371/journal.pgen.1002078

Jover, R., Bort, R., Gómez-Lechón, M. J., and Castell, J. V. (2002). Downregulation of human CYP3A4 by the inflammatory signal interleukin6: molecular mechanism and transcription factors involved. FASEB J. 16, 1799-1801.

Keshava, C., McCanlies, E. C., and Weston, A. (2004). CYP3A4 polymorphisms - potential risk factors for breast and prostate cancer: a HuGE review. Am. J. Epidemiol. 160, 825-841.

King, B. P., Leathart, J. B. S., Mutch, E., Williams, F. M., and Daly, A. K. (2003). CYP3A5 phenotypegenotype correlations in a British population. Br. J. Clin. Pharmacol. 55, 625-629.

Klees, T. M., Sheffels, P., Thummel, K. E., and Kharasch, E. D.
(2005). Pharmacogenetic determinants of human liver microsomal alfentanil metabolism and the role of cytochrome P450 3A5. Anesthesiology 102, 550-556.

Klein, K., Thomas, M., Winter, S., Nussler, A. K., Niemi, M., Schwab, M., et al. (2012). PPARA: a novel genetic determinant of CYP3A4 in vitro and in vivo. Clin. Pharmacol. Ther. 91, 1044-1052.

Klein, K., Winter, S., Turpeinen, M., Schwab, M., and Zanger, U. M. (2010). Pathway-targeted pharmacogenomics of CYP1A2 in human liver. Front. Pharmacol. 1:129. doi:10.3389/fphar.2010.00129

Koch, I., Weil, R., Wolbold, R., Brockmöller, J., Hustert, E., Burk, O., et al. (2002). Interindividual variability and tissue-specificity in the expression of cytochrome P450 3A mRNA. Drug Metab. Dispos. 30, 1108-1114.

Kuehl, P., Zhang, J., Lin, Y., Lamba, J., Assem, M., Schuetz, J., et al. (2001). Sequence diversity in CYP3A promoters and characterization of the genetic basis of polymorphic CYP3A5 expression. Nat. Genet. 27, 383-391.

Lamba, J., Lamba, V., and Schuetz, E. (2005). Genetic variants of PXR (NR1I2) and CAR (NR1I3) and their implications in drug metabolism and pharmacogenetics. Curr. Drug Metab. 6, 369-383.

Lamba, J., Lamba, V., Strom, S., Venkataramanan, R., and Schuetz, E. (2008). Novel single nucleotide polymorphisms in the promoter and intron 1 of human pregnane $\mathrm{X}$ receptor/NR1I2 and their association with CYP3A4 expression. Drug Metab. Dispos. 36, 169-181.

Lamba, J., Strom, S., Venkataramanan, R., Thummel, K. E., Lin, Y. S., Liu, W., et al. (2006). MDR1 genotype is associated with hepatic cytochrome P450 3A4 basal and induction phenotype. Clin. Pharmacol. Ther. 79, 325-338.

Lamba, V., Panetta, J. C., Strom, S., and Schuetz, E. G. (2010). Genetic predictors of interindividual variability in hepatic CYP3A4 expression. J. Pharmacol. Exp. Ther. 332, 1088-1099.

Lee, Y., Gamazon, E. R., Rebman, E., Lee, Y., Lee, S., Dolan, M. E., et al. (2012). Variants affecting exon skipping contribute to complex traits. PLoS Genet. 8:e1002998. doi:10.1371/journal.pgen.1002998

Liu, Y.-T., Hao, H.-P., Liu, C.-X., Wang, G.-J., and Xie, H.-G. (2007). Drugs as CYP3A probes, inducers, and inhibitors. Drug Metab. Rev. 39, 699-721. 
Martínez-Jiménez, C. P., GómezLechón, M. J., Castell, J. V., and Jover, R. (2005). Transcriptional regulation of the human hepatic CYP3A4: identification of a new distal enhancer region responsive to CCAAT/enhancer-binding protein beta isoforms (liver activating protein and liver inhibitory protein). Mol. Pharmacol. 67, 2088-2101.

McCune, J. S., Risler, L. J., Phillips, B. R., Thummel, K. E., Blough, D., and Shen, D. D. (2005). Contribution of Cyp3a5 to hepatic and renal ifosfamide N-dechloroethylation. Drug Metab. Dispos. 33, 1074-1081.

Miller, W. L., Agrawal, V., Sandee, D., Tee, M. K., Huang, N., Choi, J. H., et al. (2011). Consequences of POR mutations and polymorphisms. Mol. Cell. Endocrinol. 336, 174-179.

Ohtsuki, S., Schaefer, O., Kawakami, H., Inoue, T., Liehner, S., Saito, A., et al. (2012). Simultaneous absolute protein quantification of transporters, cytochromes P450, and UDP-glucuronosyltransferases as a novel approach for the characterization of individual human liver: comparison with mRNA levels and activities. Drug Metab. Dispos. 40, 83-92.

Oleson, L., Von Moltke, L. L., Greenblatt, D. J., and Court, M. H. (2010). Identification of polymorphisms in the 3'-untranslated region of the human pregnane $\mathrm{X}$ receptor (PXR) gene associated with variability in cytochrome P450 3A (CYP3A) metabolism. Xenobiotica 40, 146-162.

Oneda, B., Crettol, S., Jaquenoud Sirot, E., Bochud, M., Ansermot, N., and Eap, C. B. (2009). The P450 oxidoreductase genotype is associated with CYP3A activity in vivo as measured by the midazolam phenotyping test. Pharmacogenet. Genomics 19, 877-883.

Onizuka, M., Kunii, N., Toyosaki, M., Machida, S., Ohgiya, D., Ogawa, Y., et al. (2011). Cytochrome P450 genetic polymorphisms influence the serum concentration of calcineurin inhibitors in allogeneic hematopoietic SCT recipients. Bone Marrow Transplant. 46, 1113-1117.

Otto, D. M. E., Henderson, C. J., Carrie, D., Davey, M., Gundersen, T. E., Blomhoff, R., et al. (2003). Identification of novel roles of the cytochrome P450 System in early embryogenesis: effects on vasculogenesis and retinoic acid homeostasis. Mol. Cell. Biol. 23, 6103-6116.

Ozdemir, V., Kalow, W., Tang, B. K., Paterson, A. D., Walker, S. E., Endrenyi, L., et al. (2000).
Evaluation of the genetic component of variability in CYP3A4 activity: a repeated drug administration method. Pharmacogenetics 10, 373-388.

Pal, D., and Mitra, A. K. (2006). MDRand CYP3A4-mediated drug-drug interactions. J. Neuroimmune Pharmacol. 1, 323-339.

Pan, Y.-Z., Gao, W., and Yu, A.M. (2009). MicroRNAs regulate CYP3A4 expression via direct and indirect targeting. Drug Metab. Dispos. 37, 2112-2117.

Pascussi, J.-M., Gerbal-Chaloin, S., Duret, C., Daujat-Chavanieu, M., Vilarem, M.-J., and Maurel, P. (2008). The tangle of nuclear receptors that controls xenobiotic metabolism and transport: crosstalk and consequences. Annu. Rev. Pharmacol. Toxicol. 48, 1-32.

Patel, J., and Mitra, A. K. (2001). Strategies to overcome simultaneous P-glycoprotein mediated efflux and CYP3A4 mediated metabolism of drugs. Pharmacogenomics 2, 401-415.

Patki, K. C., Von Moltke, L. L., and Greenblatt, D. J. (2003). In vitro metabolism of midazolam, triazolam, nifedipine, and testosterone by human liver microsomes and recombinant cytochromes p450: role of cyp3a4 and cyp3a5. Drug Metab. Dispos. 31, 938-944.

Penno, M. B., Dvorchik, B. H., and Vesell, E. S. (1981). Genetic variation in rates of antipyrine metabolite formation: a study in uninduced twins. Proc. Natl. Acad. Sci. U.S.A. 78, 5193-5196.

Perera, M. A. (2010). The missing linkage: what pharmacogenetic associations are left to find in CYP3A? Expert Opin. Drug Metab. Toxicol. 6, 17-28.

Perera, M. A., Thirumaran, R. K., Cox, N. J., Hanauer, S., Das, S., BrimerCline, C., et al. (2009). Prediction of CYP3A4 enzyme activity using haplotype tag SNPs in African Americans. Pharmacogenomics J. 9, 49-60.

Piedade, R., Schaeffeler, E., Winter, S., Asimus, S., Schwab, M., Ashton, M., et al. (2012). PXR variants and artemisinin use in vietnamese subjects: frequency distribution and impact on the interindividual variability of CYP3A induction by artemisinin. Antimicrob. Agents Chemother. 56, 2153-2157.

Prueksaritanont, T., Richards, K. M., Qiu, Y., Strong-Basalyga, K., Miller, A., Li, C., et al. (2005). Comparative effects of fibrates on drug metabolizing enzymes in human hepatocytes. Pharm. Res. 22, 71-78.
Rahmioglu, N., Heaton, J., Clement, G., Gill, R., Surdulescu, G., Zlobecka, K., et al. (2011). Genetic epidemiology of induced CYP3A4 activity. Pharmacogenet. Genomics 21, 642-651.

Rahmioglu, N., Heaton, J., Clement, G., Gill, R., Surdulescu, G., Zlobecka, K., et al. (2012). Genome-wide association study reveals a complex genetic architecture underpinning-induced CYP3A4 enzyme activity. Eur. J. Drug Metab. Pharmacokinet. doi: 10.1007/s13318-012-0103-z

Rakhshandehroo, M., Hooiveld, G., Müller, M., and Kersten, S. (2009). Comparative analysis of gene regulation by the transcription factor PPAR $\alpha$ between mouse and human. PLoS ONE 4:e6796. doi:10.1371/journal.pone.0006796

Rebbeck, T. R., Jaffe, J. M., Walker, A. H., Wein, A. J., and Malkowicz, S. B. (1998). Modification of clinical presentation of prostate tumors by a novel genetic variant in CYP3A4. J. Natl. Cancer Inst. 90, 1225-1229.

Rodríguez-Antona, C., Sayi, J. G., Gustafsson, L. L., Bertilsson, L., and Ingelman-Sundberg, M. (2005). Phenotype-genotype variability in the human CYP3A locus as assessed by the probe drug quinine and analyses of variant CYP3A4 alleles. Biochem. Biophys. Res. Commun. 338, 299-305.

Rotger, M., Tegude, H., Colombo, S., Cavassini, M., Furrer, H., Décosterd L., et al. (2007). Predictive value of known and novel alleles of CYP2B6 for efavirenz plasma concentrations in HIV-infected individuals. Clin. Pharmacol. Ther. 81, 557-566.

Sadee, W. (2012). The relevance of "missing heritability" in pharmacogenomics. Clin. Pharmacol. Ther. 92, 428-430.

Sadee, W., Wang, D., Papp, A., Pinsonneault, J., Smith, R., Moyer, R., et al. (2011). Pharmacogenomics of the RNA world: structural RNA polymorphisms in drug therapy. Clin. Pharmacol. Ther. 89, 355-365.

Sandanaraj, E., Lal, S., Selvarajan, V., Ooi, L. L., Wong, Z. W., Wong, N. S., et al. (2008). PXR pharmacogenetics: association of haplotypes with hepatic CYP3A4 and ABCB1 messenger rna expression and doxorubicin clearance in Asian breast cancer patients. Clin. Cancer Res. 14, 7116-7126.

Sandee, D., Morrissey, K., Agrawal, V., Tam, H. K., Kramer, M. A., Tracy, T. S., et al. (2010). Effects of genetic variants of human P450 oxidoreductase on catalysis by CYP2D6 in vitro. Pharmacogenet. Genomics 20, 677-686.
Schadt, E. E., Molony, C., Chudin, E., Hao, K., Yang, X., Lum, P. Y., et al. (2008). Mapping the genetic architecture of gene expression in human liver. PLoS Biol. 6:e107. doi:10.1371/journal.pbio.0060107

Schirmer, M., Rosenberger, A., Klein, K., Kulle, B., Toliat, M. R., Nürnberg, P., et al. (2007). Sex-dependent genetic markers of CYP3A4 expression and activity in human liver microsomes. Pharmacogenomics 8, 443-453.

Schirmer, M., Toliat, M. R., Haberl, M., Suk, A., Kamdem, L. K., Klein, K., et al. (2006). Genetic signature consistent with selection against the CYP $3 \mathrm{~A} 4 * 1 \mathrm{~B}$ allele in non-African populations. Pharmacogenet. Genomics 16, 59-71.

Schmeier, S., Schaefer, U., MacPherson, C. R., and Bajic, V. B. (2011). dPORE-miRNA: polymorphic regulation of microRNA genes. PLoS ONE 6:e16657. doi:10.1371/journal.pone.0016657

Schröder, A., Klein, K., Winter, S., Schwab, M., Bonin, M., Zell, A., et al. (2013). Genomics of ADME gene expression: mapping expression quantitative trait loci relevant for absorption, distribution, metabolism and excretion of drugs in human liver. Pharmacogenomics J. 13, 12-20.

Shen, A. L., O'Leary, K. A., and Kasper, C. B. (2002). Association of Multiple Developmental defects and embryonic lethality with loss of microsomal NADPH-cytochrome P450 oxidoreductase. J. Biol. Chem. 277, 6536-6541.

Spurdle, A. B., Goodwin, B., Hodgson, E., Hopper, J. L., Chen, X., Purdie, D. M., et al. (2002). The CYP3A4*1B polymorphism has no functional significance and is not associated with risk of breast or ovarian cancer. Pharmacogenetics 12, 355-366.

Suhre, K., Shin, S.-Y., Petersen, A.K., Mohney, R. P., Meredith, D. Wägele, B., et al. (2011). Human metabolic individuality in biomedical and pharmaceutical research. Nature 477, 54-60.

Svärd, J., Spiers, J. P., Mulcahy, F., and Hennessy, M. (2010) Nuclear receptor-mediated induction of CYP450 by antiretrovirals: functional consequences of NR1I2 (PXR) polymorphisms and differential prevalence in whites and subSaharan Africans. J. Acquir. Immune Defic. Syndr. 55, 536-549.

Takagi, S., Nakajima, M., Mohri, T., and Yokoi, T. (2008). Posttranscriptional regulation of human 
pregnane $\mathrm{X}$ receptor by micro-RNA affects the expression of cytochrome P450 3A4. J. Biol. Chem. 283, 9674-9680.

The 1000 Genomes Project Consortium. (2010). A map of human genome variation from populationscale sequencing. Nature 467, 1061-1073.

Thomas, M., Burk, O., Klumpp, B., Kandel, B. A., Damm, G., Weiss, T. S., et al. (2013). Direct transcriptional regulation of human hepatic cytochrome P450 3A4 (CYP3A4) by peroxisome proliferatoractivated receptor alpha $(\operatorname{PPAR} \alpha)$. Mol. Pharmacol. doi:10.1124/ mol.112.082503

Thompson, E. E., Kuttab-Boulos, H., Witonsky, D., Yang, L., Roe, B. A., and Di Rienzo, A. (2004). CYP3A variation and the evolution of salt-sensitivity variants. Am. J. Hum. Genet. 75, 1059-1069.

Thompson, E. E., Kuttab-Boulos, H., Yang, L., Roe, B. A., and Di Rienzo, A. (2006). Sequence diversity and haplotype structure at the human CYP3A cluster. Pharmacogenomics J. 6, 105-114.

Wacher, V. J., Wu, C. Y., and Benet, L. Z. (1995). Overlapping substrate specificities and tissue distribution of cytochrome P450 3A and P-glycoprotein: implications for drug delivery and activity in cancer chemotherapy. Mol. Carcinog. 13, 129-134.
Wandel, C., Witte, J. S., Hall, J. M., Stein, C. M., Wood, A. J., and Wilkinson, G. R. (2000). CYP3A activity in African American and European American men: population differences and functional effect of the CYP3A4*1B5'-promoter region polymorphism. Clin. Pharmacol. Ther. 68, 82-91.

Wang, A., Yu, B.-N., Luo, C.-H., Tan, Z.-R., Zhou, G., Wang, L.-S., et al. (2005). Ile118Val genetic polymorphism of CYP3A4 and its effects on lipid-lowering efficacy of simvastatin in Chinese hyperlipidemic patients. Eur. J. Clin. Pharmacol. 60 843-848.

Wang, D., Guo, Y., Wrighton, S., Cooke, G., and Sadee, W. (2011). Intronic polymorphism in CYP3A4 affects hepatic expression and response to statin drugs. Pharmacogenomics J. 11, 274-286.

Westlind-Johnsson, A., Malmebo, S., Johansson, A., Otter, C., Andersson, T. B., Johansson, I., et al. (2003). Comparative analysis of CYP3A expression in human liver suggests only a minor role for CYP3A5 in drug metabolism. Drug Metab. Dispos. 31, 755-761.

Williams, J. A., Ring, B. J., Cantrell, V. E., Jones, D. R., Eckstein, J., Ruterbories, K., et al. (2002). Comparative Metabolic Capabilities of CYP3A4, CYP3A5, and CYP3A7. Drug Metab. Dispos. 30, 883-891.
Wrighton, S. A., Brian, W. R., Sari, M. A., Iwasaki, M., Guengerich, F. P., Raucy, J. L., et al. (1990). Studies on the expression and metabolic capabilities of human liver cytochrome P450IIIA5 (HLp3). Mol. Pharmacol. 38, 207-213.

Yang, X., Zhang, B., Molony, C., Chudin, E., Hao, K., Zhu, J., et al. (2010). Systematic genetic and genomic analysis of cytochrome P450 enzyme activities in human liver. Genome Res. 20, 1020-1036.

Yip, K. Y., Cheng, C., Bhardwaj, N., Brown, J. B., Leng, J., Kundaje, A., et al. (2012). Classification of human genomic regions based on experimentally determined binding sites of more than 100 transcriptionrelated factors. Genome Biol. 13, R48.

Zanger, U. M., Turpeinen, M., Klein, K. and Schwab, M. (2008). Functional pharmacogenetics/genomics of human cytochromes P450 involved in drug biotransformation. Anal. Bioanal. Chem. 392, 1093-1108.

Zhai, G., Teumer, A., Stolk, L., Perry, J. R. B., Vandenput, L., Coviello, A. D., et al. (2011). Eight common genetic variants associated with serum DHEAS levels suggest a key role in ageing mechanisms. PLoS Genet. 7:e1002025. doi:10.1371/journal.pgen.1002025

Zhou, S.-F., Xue, C. C., Yu, X.Q., and Wang, G. (2007). Metabolic activation of herbal and dietary constituents and its clinical and toxicological implications: an update. Curr. Drug Metab. 8, 526-553.

Zochowska, D., Wyzgal, J., and Paczek, L. (2012). Impact of CYP $3 A 4 * 1 B$ and CYP3A $5 * 3$ polymorphisms on the pharmacokinetics of cyclosporine and sirolimus in renal transplant recipients. Ann. Transplant. 17, 36-44.

Conflict of Interest Statement: The authors declare that the research was conducted in the absence of any commercial or financial relationships that could be construed as a potential conflict of interest.

Received: 18 October 2012; accepted: 26 January 2013; published online: 25 February 2013.

Citation: Klein Kand Zanger UM (2013) Pharmacogenomics of cytochrome P450 3A4: recent progress toward the "missing heritability” problem. Front. Genet. 4:12. doi: 10.3389/fgene.2013.00012

This article was submitted to Frontiers in Pharmacogenetics and Pharmacogenomics, a specialty of Frontiers in Genetics.

Copyright (C) 2013 Klein and Zanger. This is an open-access article distributed under the terms of the Creative Commons Attribution License, which permits use, distribution and reproduction in other forums, provided the original authors and source are credited and subject to any copyright notices concerning any third-party graphics etc. 